\title{
INHALT DES ZWEITEN HALBJAHRESHEFTES
}

\section{AUFSÄTZE}

Felix Albrecht, Ein griechischer Papyrus-Codex der Chronikbücher

(Ra 880, P.Sinai Gr. 1, ineditum)

Roberto Mascellari, Il saluto finale delle petizioni nei papiri di epoca

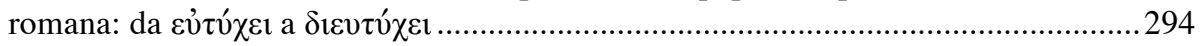

Thomas Backhuys, Vorschläge zu dokumentarischen Texten ......................................306

Andrea Bernini, Fasce di lana in un papiro latino

(P.Masada 723 riedito)

Stefanie Schmidt, P.Bas. II 70 and 71. A Look Behind the Text ....................................324

Jean-Michel Mouton, Dominique Sourdel $\dagger$, Janine Sourdel-Thomine,

Un exemple de lettre adressée à un soufi de Damas au XIIe siècle .

Maria Hermes-Wladarsch, Jörg Graf, Natriumchloridablagerungen auf den

Innenseiten der historischen Gläser von verglasten Papyrusfragmenten.

Bericht über das Projekt „Die Bremer Papyri glasklar“

\section{REFERATE}

Darstellungen und Hilfsmittel

Renate Lafer/Karl Strobel (Hgg.), Antike Lebenswelten. Althistorische und papyrologische Studien (Altertumswissenschaftliche Studien Klagenfurt [ASK], Band 4). Berlin/Boston: De Gruyter 2015 (Marius Gerhardt)

Peter Kritzinger/Frank Schleicher/Timo Stickler (Hgg.), Studien zum römischen Zollwesen. Duisburg: Wellem Verlag 2015

(Marius Gerhardt)

Volker Grieb/Krzysztof Nawotka/Agnieszka Wojciechowska (Hgg.), Alexander the Great and Egypt. History, Art, Tradition (Philippika. Altertumswissenschaftliche Abhandlungen 74). Wiesbaden: Harrassowitz 2014 (Sebastian Prignitz) 